\title{
The problem of fluid viscosity management: An interdisciplinary approach to a community-based problem emphasizing undergraduate engineering research
}

\author{
Terra L. Smith, Aaron Haga, William S. Janna \\ College of Education, The University of Memphis/ \\ The Herff College of Engineering, The University of Memphis
}

Medical errors are on-going concerns due to their relationship with patient safety. ${ }^{10}$ To heighten patient safety and medical errors concerns in the American health care community, the Institute of Medicine (IOM) published the report on entitled "To Err is Human: Building a Safer Health System." ${ }^{1}$ This report discusses two types of preventable events: serious events and less serious events. ${ }^{10}$ The type of errors addressed by this research group, inadequately prepared thickened liquids, is consider less serious events. Thus, the researchers sought out errorreduction strategies in terms of fluid preparation errors related to patients on swallowing disorders or dysphagia diets.

Speech pathologists are the lead allied health care professionals in terms of swallowing disorders. ${ }^{3}$ They diagnose the nature of swallowing disorders and recommend diet texture modifications to the attending physician. The registered dietitian and the foodservice staff are responsible for administering the diet orders and ensuring the appropriate fluid viscosity ${ }^{11}$ is prepared for patients on a dysphagia diet. Regulatory and accrediting bodies monitor how successfully the foodservice units accomplish their responsibilities to patients.

In order to help understand the nature and extent of the problem of inappropriately thickening of liquids at two facilities (with the same corporate parent company), researchers needed an inexpensive method of evaluating fluid viscosity. Researchers also needed to assess the control the fluid viscosity with methods that communicated the results understandably to the health care staff. In addition, because preliminary investigations indicated that staff needed training in the proper use of food thickeners, training materials needed to be developed. This paper discusses the nature and overview of the project, undergraduate engineering students contributions to the project, and the benefits to engineering students and community health care because of the project.

Nature of the project

This project represents service learning (SL) with community-based research (CBR) and outcomes research. This study is also reminiscent of appropriate engineering. The description of service learning that describes the project is also the description embraced by Messiah College's engineering program ${ }^{12}$ :

Service-learning is a method and philosophy of experiential learning through which participants in community service meet community needs while developing their abilities for critical thinking and group problem solving, their commitment and values and the skills needed for effective citizenship. The core elements of service-learning are (1)

"Proceedings of the 2002 American Society for Engineering Education Annual Conference \& Exposition Copyright (C) 2002, American Society for Engineering Education” 
service activities that help meet community needs that the community finds important and (2) structured educational components that challenge participants to think critically about and learn from their experiences. ${ }^{8}$

The authors of the report, "Community-based research in the United States: Executive Summary"9 describe community-based research as "research that is conducted by, with, or for communities." This project focused on meeting the needs of citizens and neighbors by focusing on concerns about the appropriateness of fluids prepared for nursing home residents. Like other CBR projects, the results were incorporated immediately, helping to justify additional foodservice costs, and helping some of society's least fortunate, nursing home residents. In addition, as with some other CBR projects, the project costs were less than anticipated in part due to foodservice staff volunteering to collect data.

The project is also characterized as outcomes research. Outcomes research is a clinical approach that connects actions of care with the patient. ${ }^{7}$ In this study, the action of care was thickening fluids according to the physician's diet prescription. Therefore, the researchers were determining if the intend to provide patients with the appropriate fluid viscosity prescription was achieved. In addition, the project had characteristics of appropriate engineering, which is a "A holistic approach to engineering design that incorporates social, political, cultural, environmental, economic, and human empowerment issues. Along with technical considerations. .." ${ }^{12}$ This project addressed a local issue with affordable technology accessible to health care staff that empowered staff and administration to reduce medical errors. The technology selected was "simple, capital saving, labor enhancing and culturally acceptable." 12

Overview of the project

Effective health care benefits the entire community. Various community members complement one another and bring unique insights, resources, and approaches to a problem. To accomplish the goals of the project a successful partnership was established among family and consumer science faculty, engineering faculty, and a long-term care dietitian that impacted engineering students, dietetic interns, and nursing home residents. Two chance meetings at university sponsored functions led to a partnership among an engineer, dietitian, and food scientist/dietitian supported by an external grant. The project's core problem addressed as identified by nursing home staff, family members of residents, and health care surveyors was fluids being inappropriately prepared for residents on swallow disorder (dysphagia) diets. Residents with dysphagia may take longer to swallow than normal, therefore, thickened fluids may be prescribed to determine inexpensive procedures for monitoring fluid consistencies, to use statistical consistencies, and to promote training of the health care students on use of food thickeners.

The project was conducted at four sites: two long-term care facilities, the mechanical engineering laboratory, and the food product development laboratory. Phase I was a preliminary study to determine appropriate data collection methods for a long-term care facility. Phase II, conducted in the engineering laboratory, was the development of procedures to characterize fluid viscosities. Phase III through V included collecting and evaluating samples of fluids prepared for residents and assessing the control of fluid consistency using statistically process control

"Proceedings of the 2002 American Society for Engineering Education Annual Conference \& Exposition Copyright $@$ 2002, American Society for Engineering Education" 
techniques, reporting to health care staff the results of the study and developing training module and training health care workers based on the results of the study. Phase VI is working toward the policy of health care workers receiving training on use of food thickeners prior to completing the initial certification or licensure process.

Summary of findings from the engineering phase

The line spread test (concentric circles) seems to give the best results. The cost of the line spread test is well under the $\$ 10$ limit. The correction chart for using the line spread test is saved as an Abobe Acrobat file. The software for this type of file is free on the Internet. The cost of the lamination on the line spread sheet is $\$ 1.50$. The $2 "$ cylinder can be found in many household items such as the cap from a can of spray paint. In this case, a hole needs to be cut in the top to fill the cap with the $1 / 4$ cup of the fluid for testing. The cylinder could also be constructed form a laminated sheet. The analysis only takes approximately 30 seconds to do once the fluid is ready to be tested.

The correction chart for using the line spread test illustrates the amount of thickener or water that may need to be added to a test fluid to reach a certain "thickness." This chart shows the amount of thickener that needs to be added to reach the goal and the amount of water needed to be added per $4 \mathrm{oz}$ of water originally in the mixture and amount of thickener added to the fluid. For instance, if water is the fluid that the patient needs and the food prepared is striving to mix 3 teaspoons of the thickener per $4 \mathrm{oz}$. of water, and the line spread test results with an average radium of 18 , then he or she will need to add $1 / 2$ teaspoon of thickener for every $4 \mathrm{oz}$. of water in the solution.

Narrative of engineering aspect of the project

Two approaches were investigated and the preliminary analysis favored the use of the concentric circles method. The first method of measuring the time for a measured amount of the fluid to pass through a funnel or a piece of tubing seems easy to model using the Bernoulli Equation $^{5,6}$ (eq. 1) but required the use of the multiple tubes or funnels for the wide range of "thicknesses":

$$
\mathrm{P}_{1} \mathrm{~g}_{\mathrm{d}} / \rho \mathrm{g}+\mathrm{V}_{1}^{2} / 2 \mathrm{~g}+\mathrm{z}_{1}=\mathrm{P}_{2} \mathrm{~g}_{\mathrm{d}} / \rho \mathrm{g}+\mathrm{V}_{2}^{2} / 2 \mathrm{~g}+\mathrm{z}_{2}(\mathrm{fL} / \mathrm{D}+\Sigma \mathrm{K}) \mathrm{V} 2 / 2 \mathrm{~g} \quad \text { Eq. } 1
$$

This equation compensates for the density and the viscosity of the fluid.

The second method of measuring the "thickness" of the fluid involves using the concentric circles. ${ }^{4}$ When a volume of fluid is dropped on a flat surface, a circle of fluid will begin to increase in diameter. In a given amount of time, the sample fluid will increase the diameter, which can be predicted with minor fluctuations. This process can be used to inform the person making the fluid sample as to whether the fluid is "too thick" to "too thin." The instructions on the thickeners compare the fluids to something they consider "syrup-like" or "honey-like". The first test fluids would actually be syrup and honey to set up a standard and then the fluids with the thickener added could be directly compared. This technique seems to be the most effective while minimizing the portion of fluid needed for testing. 
Methodology

The methodologies ${ }^{4,5,6}$ implemented by the engineering students were the following: a mixture preparation, viscometry, funnel method, and line spread test. The mixtures procedures included developing and testing different ways of measure the consistency of liquids, many mixtures with varying consistencies were prepared. Using distilled water as the first liquid tested, mixtures with concentrations ranging from 2 to 6 teaspoons of thickener were added to 4 oz of water. The concentrations were chosen from the recipe given on the thickener container and represent the different levels of the desired thickness that is required for people with dysphagia. The thinnest mixture required 2 teaspoons of thickener added per $4 \mathrm{oz}$. of water. The size of the mixtures prepared were 2 cups or $16 \mathrm{oz}$. The process was repeated for each of the other fluids.

Viscometry. A Cannon LV-6000 Rotational Viscometer was used to measure the apparent viscosity $(\mathrm{mPa})$ of the different mixtures prepared. The viscometer accomplished the measurements using four different spindles (L1, -L4) at eight different speeds $(0.3,0.6,1.5,3,6$, $12,30$ and $60 \mathrm{rpm})$. The spindles were immersed in the testing fluid and the viscometer measures the torque required to rotate the spindle at a given velocity. The viscometer used the torque, spindle speed, and the type of spindle to calculate the apparent viscosity. The apparent viscosity measurements were then divided by a correction factor to obtain the actual viscosity (Pa s). The correction factor was calculated by measuring the viscosities of 4 known fluids and obtaining data for each of the 4 spindles and the 8 speeds. The digital readout on the viscometer was compared to the actual viscosities of the fluids. A best-fit curve of this data was used to derive an equation to obtain the correction factor for each spindle at each speed. Each spindle has a minimum and a maximum viscosity it can accurately measure. The minimum viscosity that could be measured was either at a value of $95 \%$ torque or the values set forth (spindle speed in Rpm [viscosities in $\mathrm{mPa} \mathrm{s}$ ]). Therefore, certain spindles could only be used for certain mixtures to obtain accurate data.

Funnel Method. The equipment involved with this method was a funnel and a stopwatch. In order to find a relative consistency, the student researchers passed a known volume of fluid through the funnel and measured the total time for the volume to pass. This procedure was performed for various amounts of thickener added to distilled water. The times measured could be compared to determine if there is a relationship between the amount of thickener added and the time it takes for a consistent volume to evacuate. If it appears that there was a relationship present, then the system could be calibrated to predict the consistency of a unknown fluid. The experiment was performed in a funnel with a surface roughness of $15.0 \mu \mathrm{in}$. This roughness factor was obtained by means of a surface texture-measuring device manufactured by Taylor Hobson.

Line Spread Method. The line spread methodology ${ }^{4}$ included: The line-spread test uses a laminated piece of paper consisting of concentric circles equally spaced. The innermost circle is labeled " 0 " and has a diameter of 2". The subsequent circles continue to increase is diameter and are numbered from 1 to 23 and the largest circle has a diameter of 7.7 in. The average roughness factor, $\mathrm{R}_{\mathrm{a}}$, of the surface of the laminated paper is $2.5 \mu \mathrm{in}$. The other equipment used in this method is a hollow 2" diameter cylinder and a timer.

"Proceedings of the 2002 American Society for Engineering Education Annual Conference \& Exposition Copyright (C) 2002, American Society for Engineering Education" 
Results

Table 1 presents the advantages and disadvantages of the funnel versus the line spread test. The funnel was valid for a certain range of values. Therefore, if the funnel was used, it would be necessary to use a number of funnels. This would make testing different concentrations of thickener and fluid a cumbersome task. For instance, the funnel used in the test was only valid for the range of 3-4 teaspoons per $4 \mathrm{oz}$. water. Using a funnel to test the full range of water would possibly require the use of 3 different funnels.

\begin{tabular}{|c|c|c|}
\hline Tool & Advantages & Disadvantages \\
\hline Funnel & $\begin{array}{l}\text { 1. Easy to model } \\
\text { 2. Sample fluid may be served }\end{array}$ & $\begin{array}{l}\text { 1. The fluid is believed to be pseudoplastic } \\
\text { therefore the viscosity is inversely } \\
\text { proportional to velocity. } \\
\text { 2. Different funnels are necessary for different } \\
\text { thicknesses of fluids. } \\
\text { 3. If the fluid begins to dry in the funnel, the } \\
\text { roughness in the funnel would increase and } \\
\text { greatly influence the time needed. } \\
\text { The minimum serving portion will need to be } \\
\text { known. } \\
\text { 5. Results may be brand specific if the densities } \\
\text { and viscosities of different thickeners vary. } \\
\text { 6. Funnel will need to be designed with a stopper } \\
\text { to allow the fluid to settle to the bottom of the } \\
\text { funnel before allowing it to flow and be } \\
\text { measured. } \\
\text { Time needed to test at bed-side is greater than } \\
\text { that of the concentric circles. }\end{array}$ \\
\hline $\begin{array}{l}\text { Line Spread } \\
\text { Test }\end{array}$ & $\begin{array}{l}\text { 1. Only 1-2 tablespoons of fluid } \\
\text { needed for a test sample. } \\
\text { 2. Time needed to test at bed- } \\
\text { side is minimal. }\end{array}$ & $\begin{array}{l}\text { 1. Fairly difficult to model. } \\
\text { 2. A small portion of the fluid will be sacrificed } \\
\text { and will not be able to be fed to the patient. } \\
\text { 3. Administrators must have access to a } \\
\text { computer to reproduce the table accurately. }\end{array}$ \\
\hline
\end{tabular}

\section{Conclusions}

Learning is not so much additive, with new learning simply added to the old, as it is an active, dynamic process in which the connections are changed and the structure reformatted. The excitement of learning comes when new connections are made, sometimes transforming the structure, pulling apart some connections and making new ones. Sometimes new information will result in the "Aha!" experience that connects previously unrelated facts. The point is that new information results in meaningful learning when it connects with what already exists in the mind of the learner. ${ }^{2}$

The benefits of this project to undergraduate engineering students and the community can be subdivided into four categories: technical, non-technical, integration of knowledge, and community services. The technical benefits include: helping train future engineers to solve 
relevant community based problems, offering a group of engineering students the opportunity to contrast two systems of evaluating fluid viscosity, to linked subject and objective data, and practicing decision making skills. The non-technical benefits included: developing client relationship skills, experiencing the contrast between the academic and practitioner branches of another discipline, interpreting technical information into a language accessible for other professionals, and understanding how another discipline values of a subject matter. The integration of knowledge benefits included: students learning about how faculty of another discipline thinks about their work and how seemingly insignificant characteristics in a wider context can impact quality of care linking interdisciplinary ways of knowing, exposure to the values of another discipline, and integration of academic knowledge and practitioner knowledge.

The benefits to the community included helping to improve patient care; acknowledging the importance of problems identified by the family of residents, staff, and regulatory bodies, and providing data to support the decision making process. Addressing interdisciplinary communitybased problems during undergraduate engineering education benefits the community and students, promotes better decisions processes, and facilitates the integrative nature of quality education. Both SL and CBR help the learner connect existing information with 'new information resulting in meaningful learning'. ${ }^{2}$ The above quote sums up many of the benefits at the heart of the project because the project offered the students the opportunity to learn through connecting and reformulating ideals while benefiting their community. (This project was funded by the American Society for Quality, Milwaukee, Wisconsin.)

\section{Bibliography}

1. Kohn, L. T., J. M. Corrigan, and M. S. Donaldson, eds. 1999. To Err Is Human: Building a Safer Health System. Washington, DC: National Academy Press.

2. Cross, K. P. 1990. Teachers as scholars. AAHE Bulletin (December):3-4.

3. Glassburn, D. L., and J. F. Deem. 1998. Thicker viscosity in dysphagia management: Variability among speechlanguage pathologists. Dysphagia 13:218-222.

4. Grawemeyer, E. A., and M. C. Pfund. 1943. Line spread as an objective test for consistency. Food Research 8:105-108.

5. Janna, W. S. 1998. Design of Fluid Thermal Systems. 2d ed. Boston, Massachusetts: PWS Pub.

6. . 1993. Introduction to Fluid Mechanics. 3d ed. Boston, Massachusetts: PWS Pub.

7. Kane, R. L., ed. 1997. Understanding Health Care Outcomes Research. Gaithersburg, Maryland: Aspen.

8. Mintz, S., and G. Liu. 1993. Service-Learning: An overview. In National and Community Service: A Resource Guide, pp. 1-3. Washington, DC: Corporation for National Community Service. Quoted in D. Vader, C. A. Erikson, J. W. Eby. 2000. Cross-cultural service-learning for responsible engineering graduates (Washington, D. C.: American Association for Higher Education), 153-154..

9. Sclove, R. E., M. L. Scammell, and B. Holland. 1998. Community-Based Research in the United States: Executive Summary. Amherst, Massachuetts; The Loka Institute. Accessed at http//www.loka.org/CRN/summary.htm on December 20, 2001.

10. Sirota, R. L. 2000. The Institute of Medicine's Report on Medical Error: Implication for Pathology. Arch. Pathol. Lab. Med. 124:1674-1678.

11. Stanek, K., C. Hensley, and C. Van Riper. 1992. Factors affecting use of food and commercial agents to thicken liquids for individuals with swallowing disorders. J. Am. Diet. Assoc. 92(4):488-490.

12. Vader, D., C. A. Erikson, J. W. Eby. 2000. Cross-cultural service-learning for responsible engineering graduates. In Projects That Matter: Concepts and Models for Service-Learning in Engineering, ed. E. Tsang, 149-160. Washington, D. C.: American Association for Higher Education.

"Proceedings of the 2002 American Society for Engineering Education Annual Conference \& Exposition Copyright $($ C 2002, American Society for Engineering Education" 


\section{Biographical Information}

DR. TERRA L. SMITH is Assistant Professor of Consumer Science and Education of The University of Memphis's College of Education in Memphis, Tennessee. Her areas of specialization include product evaluation and undergraduate student research.

MR. AARON HAGA is a 2001 graduate of The Herff College of Engineering's undergraduate program.

DR. WILLIAM S. JANNA is Professor of Engineering and Associate Dean of Graduate Studies and Research at The University of Memphis's Herff College of Engineering. In addition to teaching undergraduate and graduate courses, his research interests include flow in piping systems, heat and mass transfer from melting ice objects, flow over a sublimating flat plate, and design of fluid-thermal systems. 